\title{
Three-dimensional nuclear magnetic resonance spectroscopy: a complementary tool to multiparametric magnetic resonance imaging in the identification of aggressive prostate cancer at 3.0T
}

\author{
Michael Deal ${ }^{1,2}$, Florian Bardet ${ }^{2}$, Paul-Michael Walker ${ }^{3,4}$, Mathilde Funes de la Vega ${ }^{5}$, Alexandre Cochet ${ }^{3,4}$, \\ Luc Cormier ${ }^{2}$, Imad Bentellis ${ }^{6}$, Romaric Loffroy ${ }^{4,7}$ \\ ${ }^{1}$ Department of Urology and Andrology, Arnault Tzanck Private Institute, Mougins Sophia-Antipolis, Mougins Cedex, France; ${ }^{2}$ Department of \\ Urology and Andrology, François-Mitterrand University Hospital, Dijon, France; ${ }^{3}$ Department of Spectroscopy and Nuclear Magnetic Resonance, \\ François-Mitterrand University Hospital, Dijon, France; ${ }^{4} \mathrm{ImViA}$ Laboratory, EA-7535, Training and Research Unit in Health Sciences, University \\ of Bourgogne/Franche-Comté, Dijon, France; ${ }^{5}$ Department of Cytology and Pathology, François-Mitterrand University Hospital, Dijon, France; \\ ${ }^{6}$ Department of Urology and Andrology, Sophia Antipolis University Hospital, Nice, France; ${ }^{7}$ Department of Radiology and Medical Imaging, \\ François-Mitterrand University Hospital, Dijon, France
}

Correspondence to: Prof. Romaric Loffroy, MD, PhD, FCIRSE. Department of Vascular and Interventional Radiology, Image-Guided Therapy Center, François-Mitterrand University Hospital, 14 Rue Paul Gaffarel, BP 77908, 21079 Dijon Cedex, France. Email: romaric.loffroy@chu-dijon.fr.

Background: The limitations of the assessment of tumor aggressiveness by Prostate Imaging Reporting and Data System (PI-RADS) and biopsies suggest that the diagnostic algorithm could be improved by quantitative measurements in some chosen indications. We assessed the tumor high-risk predictive performance of 3.0 Tesla (3.0T) multiparametric magnetic resonance imaging (mp-MRI) combined with nuclear magnetic resonance spectroscopic sequences (NMR-S) in order to show that the metabolic analysis could bring out an evocative result for the aggressive form of prostate cancer.

Methods: We conducted a retrospective study of 26 patients (mean age, 62.4 years) who had surgery for prostate cancer between 2009 and 2016 after pre-therapeutic assessment with 3.0T mp-MRI and NMR-S. Groups within the intermediate range of the D'Amico risk classification were divided into two categories, low risk ( $\mathrm{n}=20)$ and high risk ( $\mathrm{n}=6)$, according to the International Society of Urological Pathology (ISUP) 2-3 limit. Histoprognostic discordances within various risk groups were compared with the corresponding predictive MRI values. The performance of predictive models was assessed based on sensitivity, specificity, and the area under the curve (AUC) of receiver operating characteristic (ROC) curves.

Results: After prostatectomy, histological analysis reclassified 18 patients as high-risk, including 16 who were T3 MRI grade, of whom 13 (81.3\%) were found to be pT3. Among the patients who had cT1 or cT2 digital rectal examinations, the T3 MRI factor multiplied by 8.7 [odds ratio (OR), 8.7; 95\% confidence interval (CI), 1.3-56.2; $\mathrm{P}=0.024]$ the relative risk of being pT3 and by 5.8 (OR, 5.8; 95\% CI, 0.95-35.7; $\mathrm{P}=0.05$ ) the relative risk of being pGleason (pGS) > GS-prostate biopsy. Spectroscopic data showed that the choline concentration was significantly higher $(\mathrm{P}=0.001)$ in aggressive disease.

Conclusions: The predictive model of tumor aggressiveness combining mp-MRI plus NMR-S was better than the mp-MRI model alone (AUC, 0.95 vs. 0.86). Information obtained by mp-MRI coupled with spectroscopy may improve the detection of occult aggressive disease, helping in the discrimination of intermediate risks.

Keywords: Prostate cancer; magnetic resonance imaging (MRI); Prostate Imaging Reporting and Data System (PI-RADS); spectroscopy; ${ }^{1} \mathrm{H}$ magnetic resonance spectroscopic imaging ( ${ }^{1} \mathrm{H}$ MRSI); Gleason; International Society of Urological Pathology (ISUP); intermediate risks

Submitted Mar 25, 2021. Accepted for publication Apr 13, 2021.

doi: 10.21037/qims-21-331

View this article at: http://dx.doi.org/10.21037/qims-21-331 


\section{Introduction}

The correlation between the Gleason score of prostate biopsies (GS-PB) and the definitive histology of the prostatectomy specimen [prostatectomy Gleason score (pGS)] yields an overall assessment of $50 \%$, with underestimation of histological aggressiveness by prostate biopsies in over two-thirds of cases (1). This is of concern since the therapeutic decision relies chiefly on the D'Amico risk score (2). Uncertainty remains for the intermediate risk group. International Society of Urological Pathology (ISUP) 3, Gleason $4+3$ tumors would then belong to the high-risk (HR) tumor group $(3,4)$. The issue is to distinguish patients whose life expectancy exceeds 10 years and who have localized but clinically significant cancer from patients with indolent disease suitable for active surveillance (5).

The use of 3 Tesla $(3.0 \mathrm{~T})$ pelvic torso coils provides additional data for discussion and allows the creation of predictive nomograms for the extra-capsular extension (ECE) (aka T3a stages). However, their complexity still limits their use in daily practice (6-11). Moreover, 3-dimensional (3D) multivoxel nuclear magnetic resonance spectroscopy (NMR-S) also referred to as chemical shift imaging (CSI) provides non-invasive mapping of the prostatic gland based on relative changes in metabolite concentration (12-17). The diagnostic performance of this technique has proved useful in other types of cancer (18). The technique was probably abandoned due to its logistic difficulties rather than to low diagnostic value (19).

The main objective of our study was to assess the performance of 3.0T multiparametric magnetic resonance imaging (mp-MRI) combined with NMR-S for the preoperative identification of ECE (T3a stages) or extension to the seminal vesicles (ESV, T3b stages), whether occult $(\mathrm{c} T<\mathrm{pT})$ or highly aggressive (pGS > GS-BP). In other words, our aim was to show that 3D NMR-S could help in the identification of aggressive forms of prostate cancer. Our secondary objectives were to evaluate performance in ruling out cancer [negative predictive value (NPV)] or ruling out a high-grade tumor component and to assess the availability and feasibility of such tests.

\section{Methods}

\section{Study design}

We retrospectively reviewed the clinical and imaging data of all patients who had radical prostatectomy after mp-MRI examination combined with NMR-S between 2009 and
2016 (Figure 1). The study was approved by institutional ethics board of Dijon University Hospital and individual consent for this retrospective analysis was waived. The data were collected and reviewed by an expert radiologist, a senior prostate cancer expert, and a junior urologist. There were no exclusion criteria except T2-weighted (T2w) sequences that did not show obvious tumor according to the radiologist.

Indeed, we wanted to put the emphasis on the contribution of NMR-S in describing the pathological prostate metabolism. During the selection process, we identified sixty prostatectomy patients having undergone $3 \mathrm{D}$ NMR-S as part of their exploratory mp-MRI evaluation. From this reduced population, we selected only patients with a significant lesion on $\mathrm{T} 2 \mathrm{w}$ imaging: indeed, the T2w images are the main stay of the Prostate Imaging Reporting and Data System (PI-RADS) algorithm and it is relatively rare to observe signal modifications in the other multiparametric sequences in the absence of signal changes in T2. Therefore, the aim of our study was to characterize visible lesions using NMR-S and such a high selectivity process naturally led to a reduced cohort. It was an exploratory single centre study proposing an original, scientifically rigorous spectroscopic analysis.

All patients underwent a digital rectal examination (DRE), prostate-specific antigen (PSA, in $\mathrm{ng} / \mathrm{mL}$ ) assay, and a biopsy assessment [Gleason score (GS)], classifying them among the D'Amico risk groups. We also used the updated classification (4), thus defining low-risk (LR) and HR patients by dividing the intermediate range category on the Gleason 4+3, ISUP 3 limit. Thus, treated localized tumors were divided into two groups based on their recurrence risk: LR (including D'Amico low risk and low intermediate) and HR (including D'Amico high intermediate risk and very high risk) groups.

All prostatectomy specimens were evaluated at the Pathology Department by a senior physician who established the pTNM stage and GS based on hematoxylin eosin safran (HES) cell staining. Thus, the clinical data (DRE, PSA, GS) were used to define a risk level, which was compared with the histological and multiparametric imaging data.

\section{MRI protocol}

For each patient, at least 6-8 weeks were allowed to elapse between the latest intra-prostatic biopsies and the mpMRI imaging. All imaging was performed using a specific 

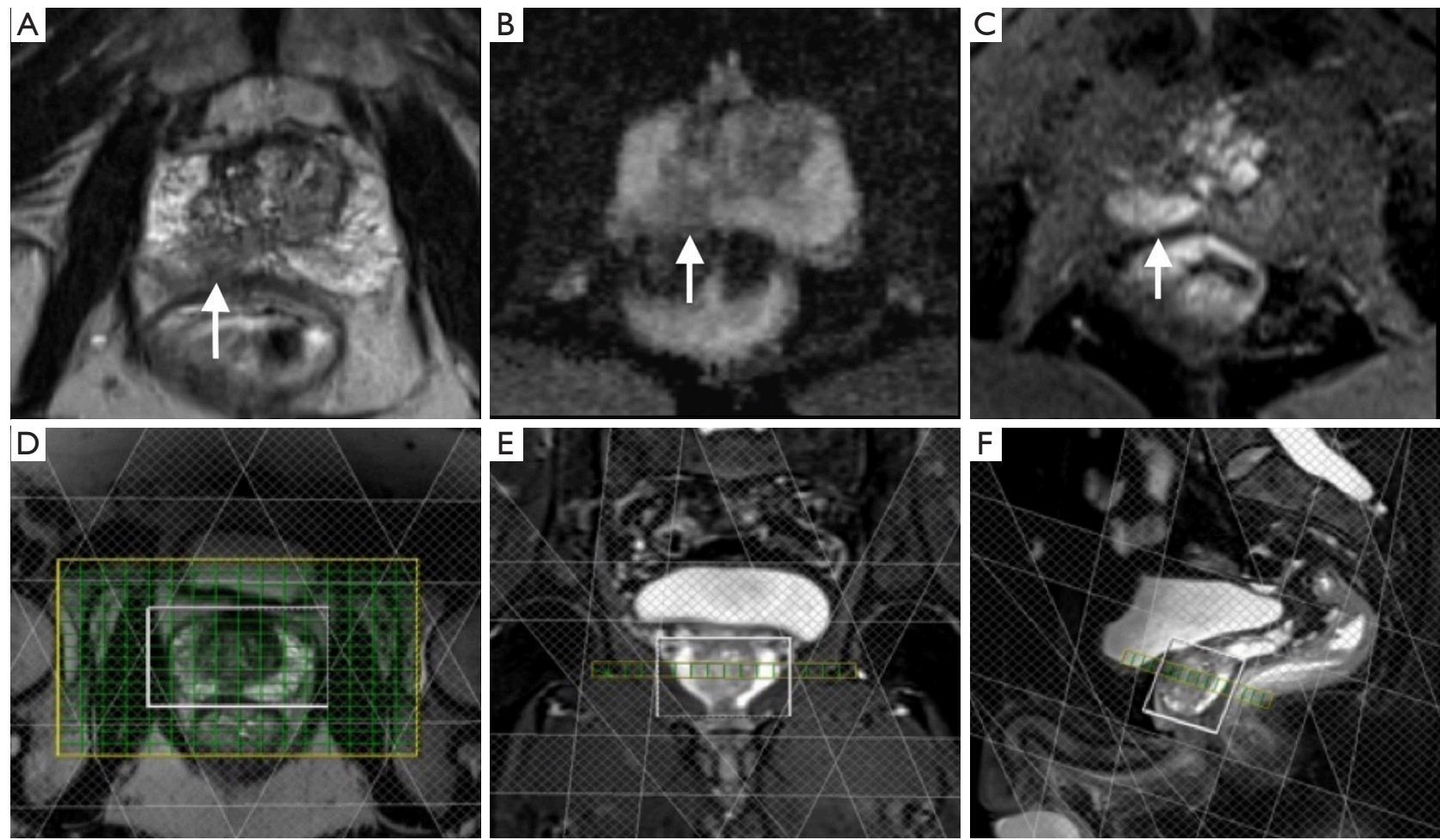

Figure 1 Typical multiparametric magnetic resonance imaging (mp-MRI) exam of the prostate on a 3.0T Trio Tim Siemens MRI unit. Axial T2-weighted (T2w) (A), diffusion-weighted imaging (DWIw) (B) and dynamic contrast-enhanced (DCEw) weighted (C) sequences through the prostatic medio-apical part, showing a hypervascular lesion with hyposignal T2 within the right peripheral zone (arrows). Axial (E), coronal (F) and sagittal (G) multi-voxel spectroscopic images performed with a phased-array torso coil and no endorectal coil (display 8 of saturation bands).

protocol that included T1-, T2-, diffusion-, and perfusionweighted imaging as well as multi-voxel spectroscopy sequences on a 3.0T Trio Trim Siemens (Erlangen, Germany) unit with a phased-array torso coil and no endorectal coil (Figure 1). The standard MRI protocol and acquisition parameters used were as follows:

* Scout sequences: the imaging was started with lowresolution gradient-echo (GE) sequences, in axial view [repetition time (TR): $20 \mathrm{~ms} /$ time to echo (TE): 5 ms/echo pulse: 1 ];

* Axial T1-weighted GE sequence: the purpose of these sequences was to eliminate post-biopsy hemorrhage (TR: $100 \mathrm{~ms} / \mathrm{TE}: 2 \mathrm{~ms} / \mathrm{echo}$ pulse: $1 /$ slice thickness: $5 \mathrm{~mm}$ ) with a $208 \times 256 \mathrm{~mm}^{2}$ field of view (FOV);

* T2w sequence in three orthogonal planes: TR: 3,600 ms/TE: $75 \mathrm{~ms} /$ slice thickness: $3.5 \mathrm{~mm}$;

* T2w fast spin echo (FSE) 3D sequence: this sequence (TR: 3,600 ms/TE: 143 ms/echo pulse: 109/slice thickness: $1.5 \mathrm{~mm}$ ) was then acquired within an axial oblique orientation perpendicular to the rectal wall. The nominal matrix was $320 \times 256 \mathrm{~mm}^{2}$, and FOV was $280 \times 240 \mathrm{~mm}^{2}$, which provided a resolution in infra-millimetric pixels;

* Diffusion-weighted imaging (DWI) sequence: axial echo-planar spin echo imaging (SE-EPI) sequence using two b-values $\left(100\right.$ and $\left.800 \mathrm{~s} / \mathrm{mm}^{2}\right)$ in all three orthogonal directions (TR: 4,200 ms/TE: 101/ bandwidth: 1,180 Hz/pixel). FOV was $240 \mathrm{~mm}$ with an acquisition matrix size of $128 \times 128$ and 3.5-mm slice thickness;

* Spectroscopic imaging: after application of saturation bands excluding the peri-prostatic tissue, rectum, and seminal vesicles, thus defining the acquisition volume of the spectra, we obtained a matrix with 16 slices, 16 lines, and 16 columns, with a 3D FOV that provided a spectral resolution of about $0.14 \mathrm{~cm}^{3}$. The spectra were sampled at 512 points with a 


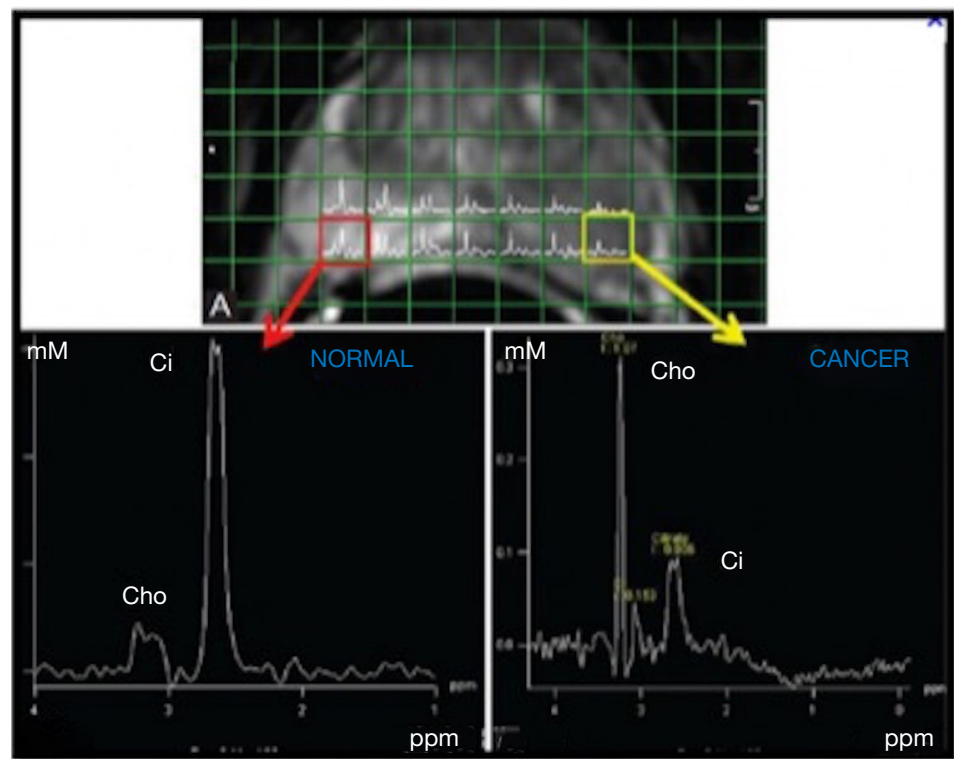

Figure 2 Spectral mapping superimposed on a T2-weighted (T2w) imaging slice. Qualitative concordance reading showing normal and pathological spectra next to the hyper- and hypo-signal regions. Ci, citrate; Cho, choline; mM, millimole; ppm, part-per-million.

1,250-Hz bandwidth (or 1,250 Hz/123.218 MHz $\approx 10.14 \mathrm{ppm}$ ). The NMR-S sequence acquisition time was 10 minutes with $\mathrm{TR}=720 \mathrm{~ms}$ and $\mathrm{TE}=140$ ms; additional spectroscopic sequences without water suppression (1.5 minutes) were acquired with the same TR values but with different TE values $(30,80$, and $140 \mathrm{~ms})$ to allow intra-prostatic water characterization in $\mathrm{T} 2$, in order to normalize the metabolites based on the water peak. A 3D Shim was systematically performed for verification of the magnetic field homogeneity and on measurement of the full width at half maximum (FWHM) of the water peak before the first acquisition: we observed a $20-30 \mathrm{~Hz}$ value within the whole volume of interest and $8-13 \mathrm{~Hz}$ for each voxel (Figure 2);

* Perfusion dynamic contrast-enhanced (DCE) sequence: the imaging ended with a DCE sequence obtained using a T1-weighted volumetric interpolated breath-hold examination 3D sequence with fat suppression (TR: $3.25 \mathrm{~ms} / \mathrm{TE}: 1.12 \mathrm{~ms} /$ flip angle: $10^{\circ}$ /matrix: $256 \times 192 / \mathrm{FOV}: 280 \times 210$ with a $75 \%$ rectangular FOV). Each acquisition had at least $163.5 \mathrm{~mm}$-thick slices with an approximate 6 s/acquisition temporal resolution, with 40 repetitions. The acquisition time of the whole sequence was approximately 4 minutes. An automatic Medrad $^{\circledR}$ injector (Bayer Healthcare, Indianola, IA,
USA) was used to enable intravenous injection of a gadolinium (Gd)-DOTA bolus (Dotarem ${ }^{\circledR}$; Guerbet, Roissy, France) in a dosage of $0.2 \mathrm{~mL}$ Gd-DOTA/kg.

\section{Collecting and processing MRI parameters}

\section{Topographic sequences (T2w MRI)}

From the data collected with the $\mathrm{T} 2$ sequences, the prostate was divided into a peripheral zone (PZ) and a central zone (CZ), then into sextants (apex, middle, base), yielding 12 zones for the final gland evaluation. The detected tumors were analyzed according to the European Society of Urogenital Radiology (ESUR) criteria and classified as T2 or T3 MRI stage depending on extra-capsular effraction or seminal vesicle involvement. The tumors could then be reclassified during the second reading, compared to the initial diagnosis.

\section{Diffusion sequences (DWI-MRI)}

Zones of interest identified in T2 images were used for the extraction of the apparent diffusion coefficient (ADC) mapping value, calculated by the MRI internal software, allowing us to get a quantitative value of the $\mathrm{ADC}$ in $\mathrm{mm}^{2} / \mathrm{s}$, calculated on a pixel-by-pixel basis.

\section{Perfusion sequences (DCE-MRI)}

The high temporal resolution of DCE sequences allowed 
the monitoring of Gd chelate contrast arrival and clearance. Several semi-quantitative or quantitative parameters can reflect the tumor microvascular permeability: time to contrast maximum peak, maximum height of contrast, the initial slope of contrast arrival ("wash-in"), the slope defining contrast clearance ("wash-out"), and the $\mathrm{k}^{\text {trans }}$ microvascular permeability factor.

In the absence of demonstrated superiority of one of these parameters over the others, we took into account the measurement of the initial slope (in $\mathrm{s}^{-1}$ ). The maximum slope was calculated using home-made computer software designed to obtain the wash-in slope coefficient, known as CWI.

\section{CSI spectroscopy sequences}

Spectra were analysed on voxels located within healthy prostate and cancer, and specifically indicated by the radiologists on T2w images. LC Model software was used to quantify Citrate (Cit), Choline (Cho) and Creatine (Cre) resonances with respect to water to yield the corresponding pseudo-absolute metabolite concentrations (expressed as $\mathrm{mM}$ ) cCit, cCho and cCre (Figure 2).

Data from the respective healthy and cancer zones were collected for ADC, CWI, cCit, and cCho. For the statistical analysis, we chose to exclude the $\mathrm{CZ}$ and to focus on both the healthy and the pathological PZ tissue.

\section{Statistical analysis}

We first described the pre-operative and post-operative clinical, histological, and imaging characteristics. Then, we compared the post-operative LR and HR groups, as well as the occult HR and actual LR groups. Patients with a risk of discordance between the pre-operative assessment and the final histology, i.e., pre-operative LR upgraded to post-operative HR, were defined as the occult HR group. Non-discordant LR patients were, by definition, actual LR patients, who were compared to the previous one. Both pre-operative and post-operative HR patients were thus excluded. We also took into account the mean values for each category of analyzed tissue.

We then compared the LR, HR, and occult HR populations by targeting voxels located only in the $\mathrm{PZ}$ of healthy tissue or pathological tissue. Initially, the mean values of these zones of interest were used, followed by the extreme values of each pathological parameter, and finally, we focused on the maximum values.

We then analyzed the performance of the MRI topographic sequences in terms of grade T3 histological predictive ability (pT3) in clinical T1 or T2 patients (cT1 or cT2). We then assessed the contribution of mp-MRI and NMR-S sequences to the T2 MRI in identifying postoperative HR. T2w+DWI+DCE MRI models such as $\mathrm{T} 2 \mathrm{w}+\mathrm{DWI}+\mathrm{DCE}+\mathrm{cCho}, \mathrm{T} 2 \mathrm{w}+\mathrm{DWI}+\mathrm{DCE}+\mathrm{cCit}$, and $\mathrm{T} 2 \mathrm{w}+\mathrm{DWI}+\mathrm{DCE}+\mathrm{cCit}+\mathrm{cCh}$ were analyzed with the mean values from healthy and pathological zones, and then with the maximum values from these same zones.

The qualitative variables were described by their frequency (percentage) and compared by the $\chi^{2}$ test, or Fisher's exact test if the sample size was small. Quantitative variables were described as mean \pm standard deviation (SD) and as median (range) and compared using the nonparametric Mann-Whitney U test.

The MRI performance for predicting pT3 stage was described by the sensitivity, specificity, positive predictive value (PPV) and NPV. Receiver operating characteristic (ROC) curves were traced to assess the performance of mp-MRI, with or without the spectroscopy parameters, for predicting pT3 disease or pGS > GS-PB, i.e., an occult HR tumor found by final histology. Different models were compared using their area under the curve (AUC). Analyses were conducted using SAS 9.3 software v. 2011 (SAS Institute, Cary, NC, USA). The chosen statistical significance level was $\mathrm{P}<0.05$.

\section{Results}

\section{Study population}

Of 182 patients treated by prostatectomy after undergoing MRI in our institution, 103 also underwent spectroscopy, including 60 who underwent 3D multivoxel spectroscopy. We selected 26 patients whose T2w imaging sequences showed an obvious tumor identified by the expert radiologist (Figure 3). These sequences were then reviewed again by a senior doctor specialized in spectroscopy and by a junior doctor not specialized in imaging, in order to select the slices to be analyzed, on which regions of interest (ROIs) containing both tumor and healthy areas were traced.

\section{Pre- and post-operative histological characteristics and MRI parameters}

At surgery, mean age of the 26 patients was 62.4 years and stages determined by DRE were T1c (38.8\%), T2a (26.9\%), T2b (19.2\%), T2c (11.9\%), and T3 (3.9\%). The mean PSA 


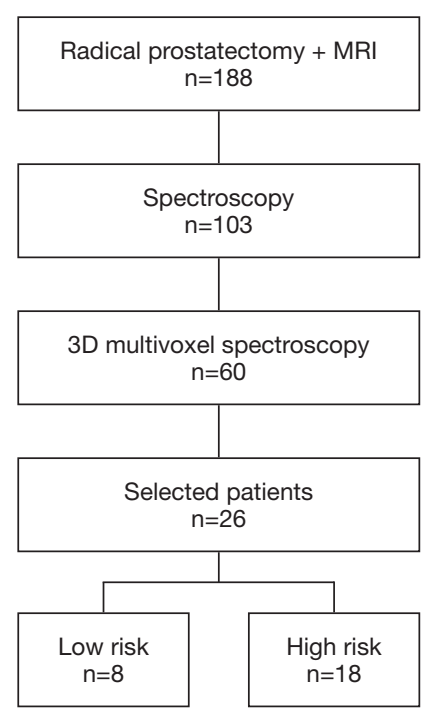

Figure 3 Study flow chart. MRI, magnetic resonance imaging; 3D, three-dimensional; n, number.

was $8.5 \mathrm{ng} / \mathrm{mL}$. The biopsies showed that $84.6 \%$ of patients were GS-PB $\leq 3+4$, and $15.4 \%$ were $\geq 4+3$. Thus, 20 patients were classified as LR and 6 patients as HR.

Among the 26 patients, 14 (53.8\%) underwent radical prostatectomy with ilio-obturator lymph node dissection, and $12(46.2 \%)$ underwent prostatectomy alone.

The MRI data classified $9(34.6 \%)$ patients as T2 MRI and $17(65.4 \%)$ patients as T3 MRI. Mean values, SDs, median ADC and CWI values, and citrate and choline concentrations for targeted zones of interest in healthy and pathological tissue are displayed in Table 1.

The histological studies of prostatectomy specimens revealed $17(65.4 \%)$ stage $\mathrm{pT} 3 \mathrm{a}$ and $\mathrm{pT} 3 \mathrm{~b}$ patients and 9 (33.6\%) pT2 patients. Post-operative GS values were $<4+3$ for $18(68.2 \%)$ patients. No surgical margin was observed for $19(73.1 \%)$ patients. The histological data with $\mathrm{pT}$ and GS, reclassified $18(70.1 \%)$ patients as post-operative HR, compared to only $6(23.1 \%)$ patients before surgery; thus $50 \%$ of patients had their tumor upgraded after prostatectomy.

\section{Post-operative LR and HR groups}

Topographic MRI data from the post-operative LR $(\mathrm{n}=8)$ and HR $(\mathrm{n}=18)$ patient groups showed a high proportion of T3 MRI findings (77.8\% vs. $37.5 \%)$ in HR patients (Tables 1,2).

The mean abnormal ADC values were markedly lower in the HR group than in the LR group, although the difference was not statistically significant $(\mathrm{P}=0.06)$. However, cCho mean values were significantly higher among $\mathrm{HR}$ patients (3.6 vs. 2.2; $\mathrm{P}=0.001)$.

\section{Occult HR and actual LR groups}

We observed that $\mathrm{ADC}$ and cCho values were within the same range as in the previous group, with choline levels significantly higher among HR patients (Table 3).

\section{Analysis of the PZ}

In the PZ, choline levels were consistently significantly higher in patients with occult HR, as well as in the preoperative HR group compared to the pre-operative LR group (cCho, 3.1 vs. 2.2; $\mathrm{P}=0.020$; and 4.1 vs. 2.7; $\mathrm{P}=0.013$, respectively) (Tables 4,5$)$.

Citrate values were always higher, regardless of the compared groups, although the difference was not statistically significant.

The steep decreasing ADC trend was confirmed among patients identified as pre-operative HR, as well as among occult HR patients. However, the difference was not statistically significant.

Regardless of the compared groups, CWI showed no significantly discriminating values between the risk groups, despite a slightly faster rise among HR patients (264.0 vs. $\left.218.7 \mathrm{~s}^{-1}\right)$.

\section{Analysis of mp-MRI + NMR-S performance}

Among our 26 patients, 25 were cT1/cT2 and 16 (64.0\%) of these 25 were cT3 MRI, including 13 (81.3\%) who were histological pT3. Thus, for LR < cT3, being T3 MRI multiplied by 8.7 the relative risk of being pT3 (OR, 8.7; 95\% CI, 1.3-56.2; $\mathrm{P}=0.024)$. In T3 MRI patients, the relative risk of being post-operative $\mathrm{HR}$, including $\mathrm{pT} 3$ Gleason score $>3+4$, was 5.8 (OR, 5.8; 95\% CI, 0.95-35.7; $\mathrm{P}=0.05)$.

The results of the predictive models are presented as ROC curves (Figures 4,5).

When looking at mean values, the AUC of $\mathrm{T} 2 \mathrm{w}+\mathrm{ADC}+\mathrm{CWI}$ sequences without NMR-S was smaller than the AUC of the model including NMR-S (0.86 vs. 0.95). The mp-MRI+NMR-S model seemed superior over the mp-MRI model alone for predicting post-operative HR status. 
Table 1 Comparing post-operative low-risk and high-risk groups

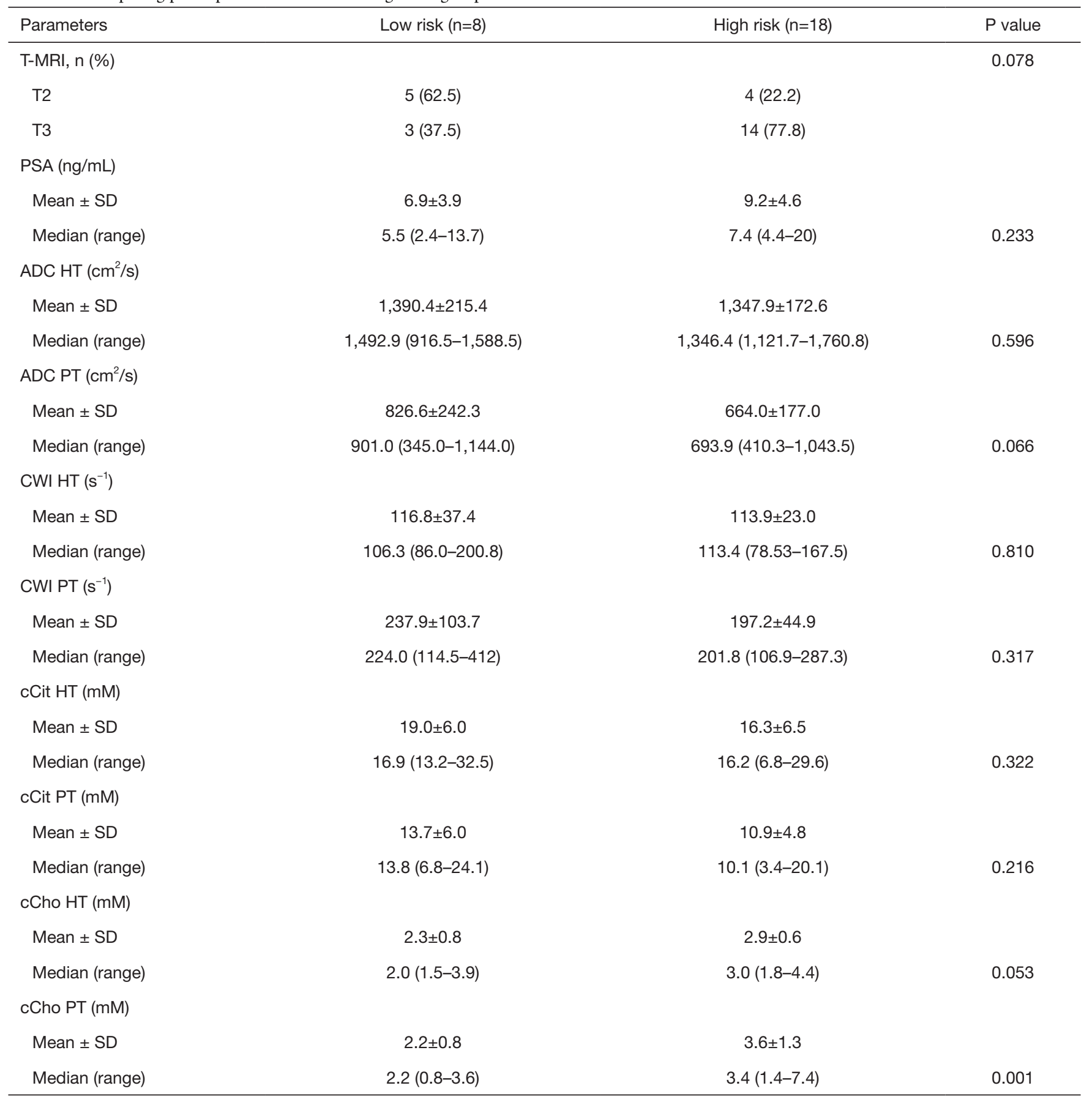

Statistical significance was established for $\mathrm{P}$ values less than 0.05. $\mathrm{n}$, number; T, tumor; MRI, magnetic resonance imaging; PSA, prostatic-specific antigen; ADC, apparent diffusion coefficient; HT, healthy tissue; PT, pathological tissue; CWI, wash-in slope coefficient; cCit, citrate concentration; cCho, choline concentration; $\mathrm{ng} / \mathrm{mL}$, nanogram per milliliter; $\mathrm{cm}^{2} / \mathrm{s}$, square centimeter per second; $\mathrm{s}^{-1}$, Hertz; $\mathrm{mM}$, millimole; SD, standard deviation. 
Table 2 Comparing post-operative low-risk and high-risk groups according to extreme values

\begin{tabular}{|c|c|c|c|}
\hline Parameters & Low risk $(\mathrm{n}=8)$ & High risk $(n=18)$ & $P$ value \\
\hline Mean \pm SD & $1,665.7 \pm 266.3$ & $1,504.3 \pm 224.4$ & \\
\hline Median (range) & $1,720.1(1,129.0-1,980.6)$ & $1,507.3(1,158.7-2,049.5)$ & 0.085 \\
\hline \multicolumn{4}{|l|}{ ADC PT $\left(\mathrm{cm}^{2} / \mathrm{s}\right)$} \\
\hline Median (range) & 704.5 (345.0-1,111.0) & $577.0(223.0-911.0)$ & 0.317 \\
\hline \multicolumn{4}{|l|}{ CWI HT $\left(\mathrm{s}^{-1}\right)$} \\
\hline Mean \pm SD & $103.1 \pm 52.6$ & $96.0 \pm 33.1$ & \\
\hline Median (range) & $88.2(63.3-222.5)$ & $86.1(65.5-193.4)$ & 0.781 \\
\hline Median (range) & $240.0(125.0-482.0)$ & $216.5(133.0-320.0)$ & 0.437 \\
\hline \multicolumn{4}{|l|}{ cCit HT (mM) } \\
\hline Mean \pm SD & $20.4 \pm 8.5$ & $17.9 \pm 7.7$ & \\
\hline Median (range) & $18.4(11.7-40.1)$ & $17.4(6.6-35.2)$ & 0.453 \\
\hline \multicolumn{4}{|l|}{ cCit PT (mM) } \\
\hline Mean \pm SD & $11.2 \pm 5.7$ & $8.7 \pm 4.2$ & \\
\hline Median (range) & $8.8(6.5-22.8)$ & $8.2(2.1-18.7)$ & 0.359 \\
\hline \multicolumn{4}{|l|}{ cCho HT (mM) } \\
\hline
\end{tabular}

Statistical significance was established for P values less than 0.05. n, number; ADC, apparent diffusion coefficient; HT, healthy tissue; PT, pathological tissue; CWI, wash-in slope coefficient; cCit, citrate concentration; cCho, choline concentration; $\mathrm{cm}^{2} / \mathrm{s}$, square centimeter per second; $\mathrm{s}^{-1}$, Hertz; mM, millimole; SD, standard deviation.

When the spectroscopic analysis took into account a single metabolite, the AUC values for citrate and choline, compared to the model without NMR-S, were 0.88 and 0.91 vs. 0.86 , respectively. We then studied the predictive power (PP) of these models for post-operative HR, using our measured maximum parameter values. We found the same results: the model that best predicted post-operative HR status was the one including the mp-MRI + NMR-S (citrate + choline), with an AUC of 0.90 vs. 0.82 with mpMRI alone.
Here as well, the use of choline alone improved the $\mathrm{PP}$ of HR (AUC $=0.88 v s$. 0.82), whereas citrate alone did not (AUC $=0.81$ ). Thus, if NMR-S sequences are performed, citrate and choline levels or choline levels only should be measured.

\section{Discussion}

The present study showed that, among patients with cT1 or cT2 DRE, the MRI factor increased the relative risk of 
Table 3 Comparing occult high-risk and actual low-risk groups

\begin{tabular}{|c|c|c|c|}
\hline Parameters & Occult high risk $(n=12)$ & Actual low risk $(n=18)$ & $P$ value \\
\hline $\mathrm{T} 2$ & $2(16.7)$ & $5(62.5)$ & \\
\hline T3 & $10(83.3)$ & $3(37.5)$ & \\
\hline \multicolumn{4}{|l|}{ PSA (ng/mL) } \\
\hline Median (range) & $6.9(4.4-19.8)$ & $5.5(2.4-13.7)$ & 0.375 \\
\hline \multicolumn{4}{|l|}{$\mathrm{ADC} \mathrm{HT}\left(\mathrm{cm}^{2} / \mathrm{s}\right)$} \\
\hline Mean $\pm S D$ & $1,381.0 \pm 194.2$ & $1,390.4 \pm 215.4$ & \\
\hline Median (range) & $1,351.8(1,144.0-1,760.8)$ & $1,492.9(916.5-1,588.5)$ & 0.643 \\
\hline Median (range) & $715.0(423.5-1,043.5)$ & $901.0(345.0-1,144.0)$ & 0.105 \\
\hline \multicolumn{4}{|l|}{ CWI HT $\left(\mathrm{s}^{-1}\right)$} \\
\hline Mean \pm SD & $111.5 \pm 24.1$ & $116.8 \pm 37.4$ & \\
\hline Median (range) & $113.7(78.5-167.5)$ & $106.3(86-200.8)$ & 0.877 \\
\hline \multicolumn{4}{|l|}{ CWI PT $\left(\mathrm{s}^{-1}\right)$} \\
\hline Mean \pm SD & $199.3 \pm 37.7$ & $237.9 \pm 151.2$ & \\
\hline Median (range) & $204.9(124.0-245.8)$ & $224.0(114.5-412.0)$ & 0.440 \\
\hline \multicolumn{4}{|l|}{ cCit HT (mM) } \\
\hline \multicolumn{4}{|l|}{ cCho HT (mM) } \\
\hline Mean \pm SD & $2.8 \pm 0.6$ & $2.3 \pm 0.8$ & \\
\hline Median (range) & $2.9(1.8-3.5)$ & $2.0(1.5-3.9)$ & 0.132 \\
\hline \multicolumn{4}{|l|}{ cCho PT (mM) } \\
\hline Mean \pm SD & $3.1 \pm 0.7$ & $2.2 \pm 0.8$ & \\
\hline Median (range) & $3.1(1.4-4.2)$ & $2.2(0.8-3.6)$ & 0.020 \\
\hline
\end{tabular}

Statistical significance was established for $\mathrm{P}$ values less than 0.05. $\mathrm{n}$, number; T, tumor; MRI, magnetic resonance imaging; PSA, prostatic-specific antigen; ADC, apparent diffusion coefficient; HT, healthy tissue; PT, pathological tissue; CWI, wash-in slope coefficient; cCit, citrate concentration; cCho, choline concentration; $\mathrm{ng} / \mathrm{mL}$, nanogram per milliliter; $\mathrm{cm}^{2} / \mathrm{s}$, square centimeter per second; $\mathrm{s}^{-1}$, Hertz; $\mathrm{mM}$, millimole; SD, standard deviation. 
Table 4 Comparing occult high-risk and actual low-risk groups in peripheral zone according to mean values

\begin{tabular}{|c|c|c|c|}
\hline Parameters & Occult high risk $(n=12)$ & Actual low risk $(n=18)$ & $P$ value \\
\hline Mean \pm SD & $1,530.0 \pm 239.6$ & $1,665.7 \pm 266.3$ & \\
\hline Median (range) & $1,507.3(1,200.2-2,049.5)$ & $1,720.1(1,129.0-1,980.6)$ & 0.143 \\
\hline \multicolumn{4}{|l|}{ ADC PT $\left(\mathrm{cm}^{2} / \mathrm{s}\right)$} \\
\hline Median (range) & $715.0(423.5-1,043.5)$ & $901.0(345.0-1,144.0)$ & 0.105 \\
\hline \multicolumn{4}{|l|}{ CWI HT $\left(\mathrm{s}^{-1}\right)$} \\
\hline Mean \pm SD & $101.1 \pm 35.2$ & $103.1 \pm 52.6$ & \\
\hline Median (range) & 94.7 (65.5-193.4) & $88.2(63.3-222.5)$ & 0.488 \\
\hline Median (range) & $204.9(124.0-245.8)$ & $224.0(114.5-412.0)$ & 0.440 \\
\hline \multicolumn{4}{|l|}{ cCit HT (mM) } \\
\hline Mean \pm SD & $20.2 \pm 7.4$ & $20.4 \pm 8.5$ & \\
\hline Median (range) & $18.6(8.5-35.2)$ & $18.4(11.7-40.1)$ & 0.969 \\
\hline \multicolumn{4}{|l|}{ cCit PT (mM) } \\
\hline Mean \pm SD & $11.2 \pm 4.9$ & $13.7 \pm 6.0$ & \\
\hline Median (range) & $10.3(3.4-20.1)$ & $13.8(6.8-24.1)$ & 0.375 \\
\hline \multicolumn{4}{|l|}{ cCho HT (mM) } \\
\hline
\end{tabular}

Statistical significance was established for $\mathrm{P}$ values less than 0.05. n, number; ADC, apparent diffusion coefficient; HT, healthy tissue; PT, pathological tissue; CWI, wash-in slope coefficient; cCit, citrate concentration; cCho, choline concentration; $\mathrm{cm}^{2} / \mathrm{s}$, square centimeter per second; $\mathrm{s}^{-1}$, Hertz; mM, millimole; SD, standard deviation.

being pT3 by more than 8 -fold and the risk of being pGS > GS-PB by more than 5 -fold. The spectroscopic data showed that the choline concentration was significantly higher in patients with aggressive disease. The predictive model of tumor aggressiveness combining mp-MRI and NMR-S performed better than the mp-MRI model alone.

mp-MRI, notably coupled with NMR-S, improves the performance of the D'Amico predictive model (20). Each MRI sequence produces different predictions, but combining all the sequences optimizes performance, whether it is for identifying cancer, for evaluating the length of capsular contact (CC) and the ECE (21), or for predicting aggressiveness $(22,23)$ or predicting very $L R$ forms, as suggested by Shukla-Dave et al. (24), with a very $\operatorname{good}$ NPV.

As seen in our cohort, many HR patients are T3 MRI, and of these, four-fifths are pT3 upon final histology. Many studies have assessed MRI performance in detecting prostate tumors based on their size and on the evaluation of CC and ECE (20,25-27). Reported sensitivity, specificity, and positive and NPVs for tumor detection are about $74 \%$, $88 \%, 84 \%$, and $78 \%$, respectively. Performance tends to 
Table 5 Comparing occult high-risk and actual low-risk groups in the peripheral zone according to maximum values

\begin{tabular}{|c|c|c|c|}
\hline Parameters & Occult high risk ( $n=12)$ & Actual low risk $(n=18)$ & $P$ value \\
\hline \multicolumn{4}{|l|}{$\mathrm{ADC} \mathrm{HT}\left(\mathrm{cm}^{2} / \mathrm{s}\right)$} \\
\hline Mean \pm SD & $1,530.0 \pm 239.6$ & $1,665.7 \pm 266.3$ & \\
\hline Median (range) & $1,507.3(1,200.2-2,049.5)$ & $1,720.1(1,129.0-1,980.6)$ & 0.143 \\
\hline \multicolumn{4}{|l|}{ ADC PT $\left(\mathrm{cm}^{2} / \mathrm{s}\right)$} \\
\hline Median (range) & $577.0(223.0-911.0)$ & $704.5(345.0-1,111.0)$ & 0.316 \\
\hline \multicolumn{4}{|l|}{ CWI HT $\left(\mathrm{s}^{-1}\right)$} \\
\hline Mean \pm SD & $101.1 \pm 35.2$ & $103.1 \pm 52.6$ & \\
\hline Median (range) & $94.7(65.5-193.4)$ & $88.2(63.3-222.5)$ & 0.488 \\
\hline Median (range) & $218.5(133.0-290.0)$ & $240.0(125.0-482.0)$ & 0.478 \\
\hline \multicolumn{4}{|l|}{ cCit HT (mM) } \\
\hline Mean \pm SD & $20.2 \pm 7.4$ & $20.4 \pm 8.5$ & \\
\hline Median (range) & $18.6(8.5-35.2)$ & $18.4(11.7-40.1)$ & 0.969 \\
\hline \multicolumn{4}{|l|}{ cCit PT (mM) } \\
\hline Mean \pm SD & $8.8 \pm 4.0$ & $11.2 \pm 5.7$ & \\
\hline Median (range) & $8.4(2.1-18.7)$ & $8.8(6.5-22.8)$ & 0.671 \\
\hline \multicolumn{4}{|l|}{ cCho HT (mM) } \\
\hline
\end{tabular}

Statistical significance was established for $\mathrm{P}$ values less than 0.05. n, number; ADC, apparent diffusion coefficient; HT, healthy tissue; PT, pathological tissue; CWI, wash-in slope coefficient; cCit, citrate concentration; cCho, choline concentration; $\mathrm{cm}^{2} / \mathrm{s}$, square centimeter per second; $\mathrm{s}^{-1}$, Hertz; mM, millimole; SD, standard deviation.

decrease for detecting tumors in the apex, a zone that is difficult to study, as shown by several studies $(27,28)$. These detection values apply to all tumors greater than $0.1 \mathrm{~cm}^{3}$.

Several specialized teams have shown that adding spectroscopy to MRI protocols improves detection specificity, as well as the characterization of prostate cancers (29). Leapman et al. (30) demonstrated that proton spectroscopy improved the discrimination of high-grade prostate cancers when combined with PI-RADS-version 2 (PI-RADS-v2), particularly for score 4 lesions, whereas the prediction of ECE was not affected. In 2009, a clinical trial by the American College of Radiology Imaging Network (ACRIN) determined that NMR-S had no added value compared to the $\mathrm{T} 2 \mathrm{w}$ imaging in separating sextant biopsies with and without prostate cancer (31). The absence of difference in sensitivity after stratification on the GS may be related to selection bias, which is common in studies on this topic. The loss of interest in this technique was likely reinforced by the PI-RADS group, who determined that it was optional to DWI (32) and later excluded it from guidelines (33).

Shukla-Dave et al. (24) emphasized the good 

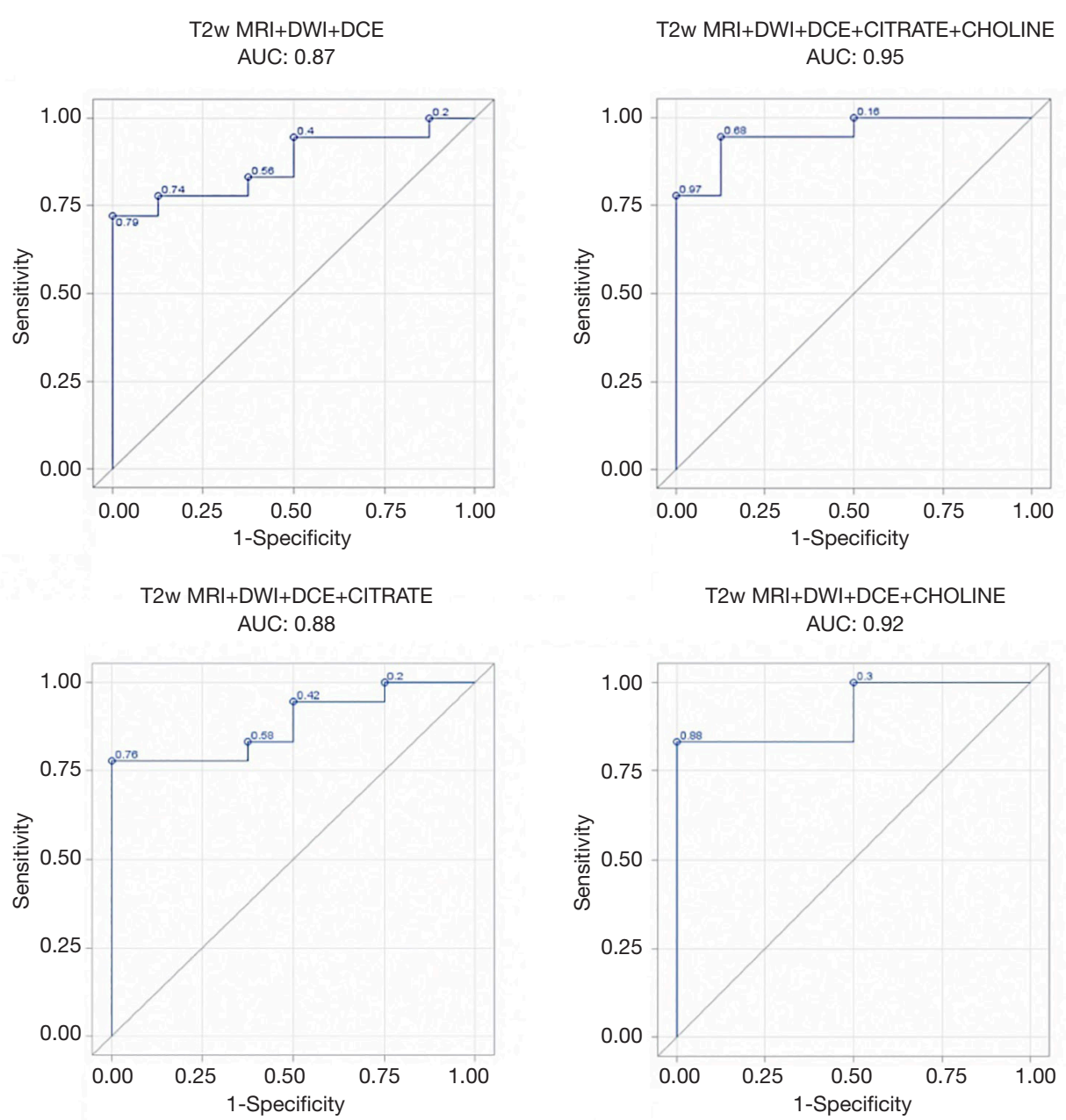

Figure 4 Comparing different high-risk predictive models based on the mean values of measured parameters. AUC, area under the curve. T2w MRI, T2-weighted magnetic resonance imaging; DWI, diffusion-weighted imaging; DCE, dynamic contrast-enhanced.

performance of NMR-S for eliminating significant tumor. They also insisted on the difficulty in interpreting the $\mathrm{CZ}$, where many false positives were observed due to the challenges in differentiating adenomatous tissue from malignant tissue. For this reason, we limited our study to the $\mathrm{PZ}$, which is easier to analyze. These data were reviewed by Zakian et al. (34), who also validated NMR-S only for the PZ. Other studies, notably by Heuck et al. and $\mathrm{Yu}$ et al. $(35,36)$, demonstrated that adding NMR-S to MRI significantly improved the accuracy of prostate cancer detection, determined by examining the radical prostatectomy specimens. Thörmer et al. (37) reported that adding MRI to ultrasound for guiding transrectal biopsies improved diagnostic yield and that biopsies directed by DWI performed better than biopsies directed by MR spectroscopy in the PZ. In a study of 64 patients, Polanec et al. (38) found that coupling spectroscopic sequences with mp-MRI did not improve tumor detection but resulted in better prediction of tumor grade.

However, these data reveal that spectroscopic sequences can help to eliminate aggregated tumor cells in any part of the gland, in the absence of tumor detection by both topographic and dynamic sequences. The T3 MRI criterion is usually established based on direct or indirect CC or ECE on T2w sequences. Consequently, in our study, NMR-S did not contribute to assess the T3 criterion, and its results were only reported as consistent or not with the data from mp-MRI. In our opinion, this is not the main benefit provided by NMR-S.

Spectroscopic sequences perform well in predicting 

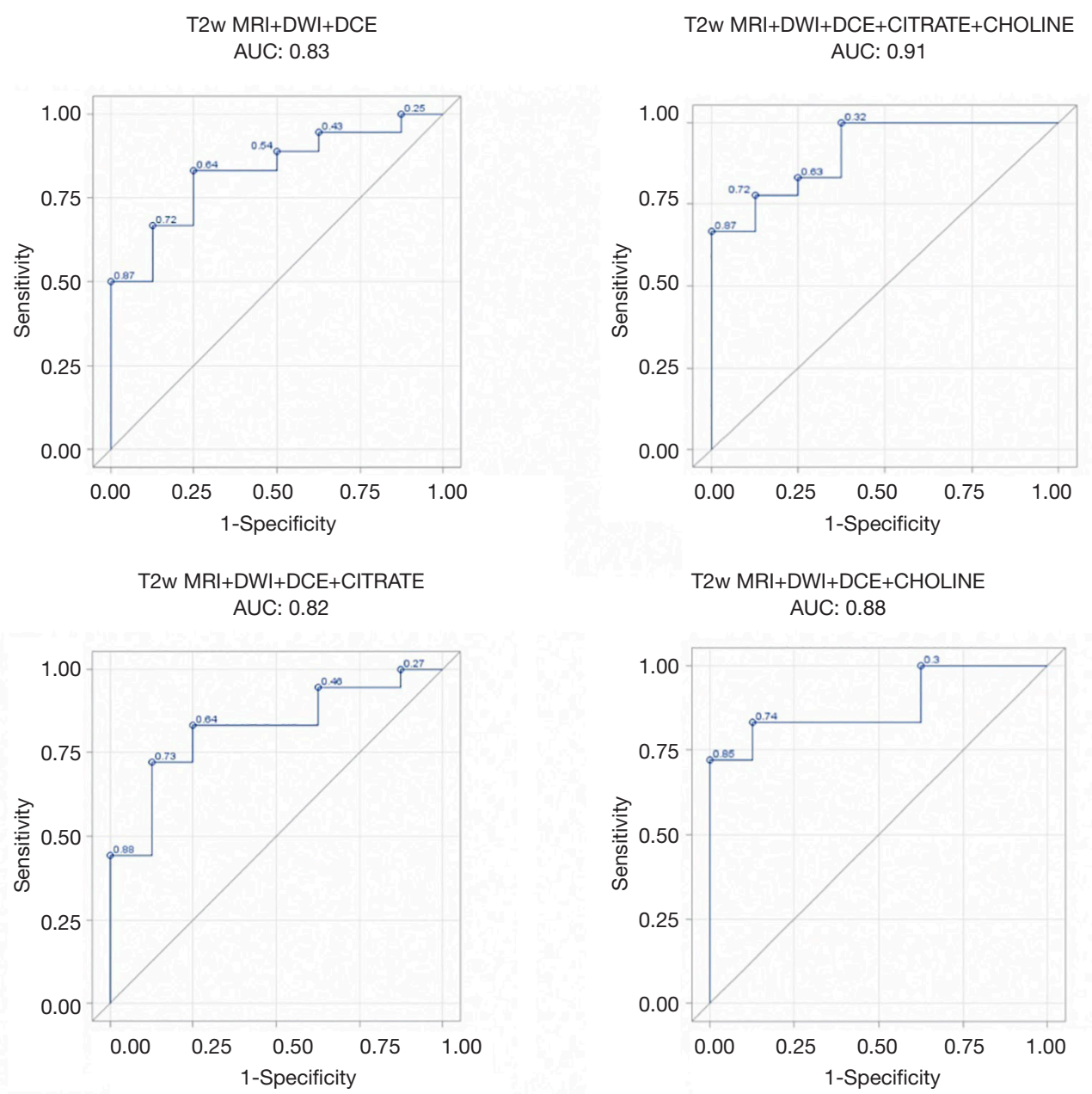

Figure 5 Comparing different high-risk predictive models based on the extreme values of measured parameters. AUC, area under the curve. T2w MRI, T2-weighted magnetic resonance imaging; DWI, diffusion-weighted imaging; DCE, dynamic contrast-enhanced.

HR tumors (39). The GS correlates with aggressiveness, particularly on diffusion sequences, where the ADC has an inverse correlation with the Gs $(40,41)$. The performance of mp-MRI in identifying aggressive forms increases when spectroscopic sequences are added; the detection threshold increases with the GS, as reported by Zakian et al. (34): the proportion of detected tumors was $44 \%, 76 \%, 86 \%$, and $89 \%$ for GS values of $3+3,3+4,4+3$, and $4+4$, respectively. It would seem that NMR-S is mainly used to detect aggressive forms, similarly to diffusion sequences.

Incidentally, in a Norwegian study published in 2013 (42), ADC values decreased with the GS, and the difference was significant between LR and HR tumors but not between LR and intermediate tumors. These results confirm that, when dealing with an aggressive tumor, the appearance of the spectra and dynamic sequences reflect not only the citrate and choline concentrations but also the proliferative and neo-angiogenic potential, and is therefore markedly different from findings with LR tumors. Accordingly, we found significantly higher choline levels in HR tumors. Our quantitative data confirm that the spectral alterations are greatest with aggressive tumors. On the other hand, predicting the absence of an HR tumor to determine whether active surveillance is appropriate can rely on the high NPV of mp-MRI coupled with NMR-S. The dynamic and spectroscopic maps provided by multimodal MRI can thus make a major contribution to patient selection for active surveillance (43). It may also have significant impact on the need for hormonotherapy concomitant to radiotherapy. Lastly, it could play an important role in the 
type of surgical intervention that will be offered to patients, combining or not lymphadenectomy and preventing or not surgical margins.

The relationship between tumor aggressiveness and increased choline metabolism has already been studied in a number of series. The correlation is readily accepted and the use in routine of ${ }^{11} \mathrm{C}$-Choline PET in the study of prostate cancer as well as hepatocellular carcinoma $(44,45)$. As for the physiopathological explication, choline is involved in the lipid metabolism notably membrane, but also as a methyl donor. It is involved in the methylation of DNA and can lead to perturbation in its repair. Choline may also modify cell signaling mediated by phospholipid metabolites. Indeed, choline underpins cell membrane synthesis and will, therefore, favorize cellular proliferation. Moreover, higher levels of choline in blood plasma and tissues have been associated with increased risk of cancer. In the event of tumor growth or oncogenesis, the lipid metabolism is increased by phospholipid genesis, a principal component of cell membranes (45). An accelerated, unregulated cell growth will increase choline kinase expression and this enzyme will phosphorolyse the choline and initiate its passage into the intracellular space via a transporter in the form of phosphatidylcholine from cell membranes. An increase in its concentration should allow detection through different imaging modalities (45). Citrate metabolism in prostate cancer has been used as another marker of aggressiveness $(44,45)$. The absence of significant difference in citrate concentration alone between groups in our study might be explained by the lack of power because of the small sample size.

One of the main disadvantages of radiotherapy treatment alone, by external beam or brachytherapy, is the absence of a definitive diagnosis based on histological material, which carries a risk of under-staging. The specificity of HR prediction is thus particularly important when using radiotherapy, and the use of modern assessment tools makes under-staging highly unlikely. One of the strengths of our study is that the dynamic sequences, and most notably the spectroscopic assessment, were conducted in a quantitative manner, whereas most recent studies of NMR-S were qualitative. The potential for subjectivity altering the discrimination of pathological spectra was limited, since we compared measured values. However, it remains difficult to define cutoffs for GS and citrate/choline values, because deep gaps typically occur, perhaps due to measurement and inter-individual variability. The higher choline values in HR tumors were consistently found across groups. Thus, the values were significantly higher not only in the preoperative HR group but also in the occult HR group, i.e., in patients whose tumor aggressiveness was underestimated before surgery. In our cohort, increased choline was a major staging marker. These findings need to be further evaluated in larger studies.

Our study has several limitations. First, our study has the limitations inherent in the retrospective design. The sample size was small and affected by selection bias. With respect to the possible selection bias, we need to clarify our reasoning. At the onset of the study, we wanted to put the onus on the contribution of ${ }^{1} \mathrm{H}$ MR spectroscopy in describing pathological prostate metabolism. During the selection process, we identified 103 prostatectomy patients who had undergone MR spectroscopy and 60 of these patients underwent 3D MR spectroscopy, specifically. From this reduced population, we selected only patients with a significant lesion on $\mathrm{T} 2 \mathrm{w}$ imaging: indeed, a number of patients had relatively small lesions and MR spectroscopy is notoriously poor when lesion size is less than $0.5 \mathrm{~cm}^{3}$. Moreover, the $\mathrm{T} 2 \mathrm{w}$ images are the main stay of the PIRADS algorithm and it is relatively rare to observe signal modifications in the other multiparametric sequences in the absence of signal changes in T2. The aim of this article was, therefore, to evaluate metabolic markers of tumoral aggressiveness on significant lesions already identified on T2w images. The spectra from these pathological regions were then compared with spectra acquired within contralateral non-pathological tissue. In doing so, we focalized our attention on sample homogeneity rather than take the risk of diluting of data sets in the search for a larger cohort. Our study had an exploratory nature from the start in order to highlight specific metabolic information. A fullscale study would obviously require a different approach to patient selection. Second, to study the quantitative spectroscopic characteristics of the tumors, we selected MRIs based on clear tumor visibility on $\mathrm{T} 2 \mathrm{w}$ images. This explains the high proportion of T3 MRI tumors in our cohort. Assessing the ability of T3 MRI to predict pT3 would require reading of the images by two radiologists working independently, since the interpretation of CC and ECE depends heavily on the radiologist's expertise (46). Third, regarding the analysis methodology, it would be interesting to standardize the number of exploitable slices and voxels for each patient and to focus only on the measurement values for ADC, CWI, and metabolite concentrations in the PZ. Indeed, selection bias occurs when requiring highly detailed MRI and NMR-S images, 
as reported by Lagemaat et al. (47), who found that NMR-S was reproducible only after excluding $35 \%$ of the voxels because of their poor quality. Another limitation is the post hoc nature of the analysis. Last, regarding the availability and feasibility of such imaging studies, the performance and interpretation of prostate MRI scans varies widely in daily practice despite the standardization of protocols by scientific societies. Acquiring and interpreting NMR-S sequences requires a particularly high level of expertise. The whole process, from purchase to manipulation, including storing and eliminating the consumables, would be difficult to implement in everyday practice. The interpretation of spectroscopic sequences requires specific expertise to select the studied volume by saturation band placement and to assess suspicious zones and measure the area under peak, in order to obtain exploitable metabolic measurement values. Thus, NMR-S is generally available only in centers with a very high level of expertise (48). Furthermore, it can be time-consuming both in terms of sequence acquisition and software post-treatment, making spectroscopy difficult to routinely implement in all prostate MRI exams, at least in France. In the future, automating the procedure with a single sampling technician (49), together with other improvements, may make NMR-S more widely available $(50,51)$. These new sequences can be used with a pelvic phased array (52). Also, the limitations of PI-RADS are now well known (53) and further support the incorporation of quantitative tools into the diagnostic algorithm (54).

\section{Conclusions}

In conclusion, the quantitative analysis of spectroscopic sequences coupled with DCE sequences improves the characterization of HR tumors compared to multiparametric sequences alone. A high choline concentration appears to be a specific marker for aggressive prostate disease. Thus, the identification of elevated intracellular choline in the $\mathrm{T} 2 \mathrm{w}$ MRI pathological zone improves the detection of aggressive forms of prostate cancer. On a larger scale, such as in a multicentric and prospective approach, we suggest that this tool could be useful given the encouraging results found in our small exploratory series.

The metabolic information provided by spectroscopy, as well as dynamic sequences, appear to be of major interest when selecting patients for active surveillance protocols. Finally, it would be of interest to assess the mp-MRI and NMR spectroscopic profiles of the different types of benign and malignant prostate tissues in the CZ. Current technological advances, notably in image acquisition processes, make this quantitative technique particularly relevant, given the limitations of PI-RADS.

\section{Acknowledgments}

Funding: None.

\section{Footnote}

Conflicts of Interest: All authors have completed the ICMJE uniform disclosure form (available at http://dx.doi. org/10.21037/qims-21-331). Dr. RL serves as an unpaid editorial board member of Quantitative Imaging in Medicine and Surgery. The other authors have no conflicts of interest to declare.

Ethical Statement: The authors are accountable for all aspects of the work in ensuring that questions related to the accuracy or integrity of any part of the work are appropriately investigated and resolved. The study was conducted in accordance with the Declaration of Helsinki (as revised in 2013). The study was approved by institutional ethics board of Dijon University Hospital and individual consent for this retrospective analysis was waived.

Open Access Statement: This is an Open Access article distributed in accordance with the Creative Commons Attribution-NonCommercial-NoDerivs 4.0 International License (CC BY-NC-ND 4.0), which permits the noncommercial replication and distribution of the article with the strict proviso that no changes or edits are made and the original work is properly cited (including links to both the formal publication through the relevant DOI and the license). See: https://creativecommons.org/licenses/by-nc-nd/4.0/.

\section{References}

1. Kvåle R, Møller B, Wahlqvist R, Fosså SD, Berner A, Busch C, Kyrdalen AE, Svindland A, Viset T, Halvorsen OJ. Concordance between Gleason scores of needle biopsies and radical prostatectomy specimens: A population-based study. BJU Int 2009;103:1647-54.

2. D'Amico AV, Whittington R, Malkowicz SB, Schultz D, Blank K, Broderick GA, Tomaszewski JE, Renshaw AA, Kaplan I, Beard CJ, Wein A. Biochemical outcome after radical prostatectomy, external beam radiation therapy, or interstitial radiation therapy for clinically localized prostate 
cancer. JAMA 1998;280:969-74.

3. Egevad L, Delahunt B, Srigley JR, Samaratunga H. International Society of Urological Pathology (ISUP) grading of prostate cancer - An ISUP consensus on contemporary grading. APMIS 2016;124:433-5.

4. D'Amico AV, Moul J, Carroll PR, Sun L, Lubeck D, Chen $\mathrm{MH}$. Cancer-specific mortality after surgery or radiation for patients with clinically localized prostate cancer managed during the prostate-specific antigen era. J Clin Oncol 2003;21:2163-72.

5. Mohler JL, Kantoff PW, Armstrong AJ, Bahnson RR, Cohen M, D'Amico AV, Eastham JA, Enke CA, Farrington TA, Higano CS, Horwitz EM, Kane CJ, Kawachi MH.; Kuettel, M, Kuzel TM, Lee RJ, Malcolm AW, Miller D, Plimack ER, Pow-Sang JM, Raben D, Richey S, Roach 3rd M, Rohren E, Rosenfeld S, Schaeffer E, Small EJ, Sonpavde G, Srinivas S, Stein C, Strope SA, Tward J, Shead DA, Ho M. National Comprehensive Cancer Network. Prostate cancer, version 2.2014. J Natl Compr Canc Netw 2014;12:686-718.

6. Pepe P, Garufi A, Priolo G, Pennisi M. Can 3-Tesla pelvic phased-array multiparametric MRI avoid unnecessary repeat prostate biopsy in patients with PSA $<10 \mathrm{ng} / \mathrm{mL}$ ? Clin Genitourin Cancer 2015;13:e27-30.

7. Kim BS, Kim TH, Kwon TG, Yoo ES. Comparison of pelvic phased-array versus endorectal coil magnetic resonance imaging at 3 Tesla for local staging of prostate cancer. Yonsei Med J 2012;53:550-6.

8. Monni F, Fontanella P, Grasso A, Wiklund P, Ou YC, Randazzo M, Rocco B, Montanari E, Bianchi G. Magnetic resonance imaging in prostate cancer detection and management: a systematic review. Minerva Urol Nefrol 2017;69:567-78.

9. Koie T, Mitsuzuka K, Narita S, Yoneyama T, Kawamura S, Tsuchiya N, Tochigi T, Habbuchi T, Arai Y, Ohyama C. Efficiency of pretreatment risk stratification systems for prostate cancer in a Japanese population treated with radical prostatectomy. Int J Urol 2015;22:70-3.

10. Panda A, O Connor G, Lo WC, Jiang Y, Margevicius S, Schluchter M, Ponsky LE, Gulani V. Targeted biopsy validation of peripheral zone prostate cancer characterization with magnetic resonance fingerprinting and diffusion mapping. Invest Radiol 2019;54:485-93.

11. Loffroy R, Chevallier O, Moulin M, Favelier S, Genson PY, Pottecher P, Crehange G, Cochet A, Cormier L. Current role of multiparametric magnetic resonance imaging for prostate cancer. Quant Imaging Med Surg 2015;5:754-64.
12. Brown TR, Kincaid BM, Ugurbil K. NMR chemical shift imaging in three dimensions. Proc Natl Acad Sci U S A 1982;79:3523-6.

13. Kurhanewicz J, Vigneron DB, Nelson SJ, Hricak H, MacDonald JM, Konety B, Narayan P. Citrate as an in vivo marker to discriminate prostate cancer from benign prostatic hyperplasia and normal prostate peripheral zone: detection via localized proton spectroscopy. Urology 1995;45:459-66.

14. Cai W, Zhu D, Byanju S, Chen J, Zhang H, Wang Y, Liao M. Magnetic resonance spectroscopy imaging in diagnosis of suspicious prostate cancer: A meta-analysis. Medicine (Baltimore) 2019;98:e14891.

15. Zadra G, Loda M. Metabolic vulnerabilities of prostate cancer: Diagnostic and therapeutic opportunities. Cold Spring Harb Perspect Med 2018;8:a030569.

16. Zhang VY, Westphalen A, Delos Santos L, Tabatabai ZL, Shinohara K, Vigneron DB, Kurhanewicz J. The role of metabolic imaging in radiation therapy of prostate cancer. NMR Biomed 2014;27:100-11.

17. Cornel EB, Smits GA, Oosterhof GO, Karthaus HF, Deburyne FM, Schalken JA, Heerschap A. Characterization of human prostate cancer, benign prostatic hyperplasia and normal prostate by in vitro $1 \mathrm{H}$ and $31 \mathrm{P}$ magnetic resonance spectroscopy. J Urol 1993;150:2019-24.

18. Pinker K, Bogner W, Baltzer P, Gruber S, Bickel H, Brueck B, Trattnig S, Weber M, Dubsky P, Bago-Horvath Z, Bartsch R, Helbich TH. Improved diagnostic accuracy with multiparametric magnetic resonance imaging of the breast using dynamic contrast-enhanced magnetic resonance imaging, diffusion-weighted imaging, and 3-dimensional proton magnetic resonance spectroscopic imaging. Invest Radiol 2014;49:421-30.

19. Westphalen AC. Lost in translation: Lessons learned from the « demise » of MRSI of the prostate. Abdom Radiol (NY) 2019;44:3185-7.

20. Seitz M, Shukla-Dave A, Bjartell A, Touijer K, Sciarra A, Bastian PJ, Stief C, Hricak H, Graser A. Functional magnetic resonance imaging in prostate cancer. Eur Urol 2009;5 5:801-14.

21. Albert T, Pasquali R, Giusiano S, Roland G, Rossi D, Bastide C. Value of MRI in detection of extracapsular extension in prostate cancer: a prospective study comparing imaging and histology. Prog Urol 2014;24:102-7.

22. Thompson J, Lawrentschuk N, Frydenberg M, Thompson L, Stricker P. The role of magnetic resonance imaging in 
the diagnosis and management of prostate cancer. BJU Int 2013;112:6-20.

23. Sankineni S, Osman M, Choyke PL. Functional MRI in prostate cancer detection. BioMed Res Int 2014;2014:590638.

24. Shukla-Dave A, Hricak H, Kattan MW, Pucar D, Kuroiwa K, Chen HN, Spector J, Koutcher JA, Zakian KL, Scardino PT. The utility of magnetic resonance imaging and spectroscopy for predicting insignificant prostate cancer: an initial analysis. BJU Int 2007;99:786-93.

25. Bloch BN, Genega EM, Costa DN, Pedrosa I, Smith MP, Kressel HY, Ngo L, Sanda MG, Dewolf WC, Rofsky NM. Prediction of prostate cancer extracapsular extension with high spatial resolution dynamic contrast-enhanced 3-T MRI. Eur Radiol 2012;22:2201-10.

26. Rosenkrantz AB, Chandarana H, Gilet A, Deng FM, Babb JS, Melamed J, Taneja SS. Prostate cancer: Utility of diffusion-weighted imaging as a marker of side-specific risk of extracapsular extension. J Magn Reson Imaging 2013;38:312-9.

27. Torricelli P, Barberini A, Cinquantini F, Sighinolfi M, Cesinaro AM. 3-T MRI with phased-array coil in local staging of prostatic cancer. Acad Radiol 2008;15:1118-25.

28. Sciarra A, Barentsz J, Bjartell A, Eastham J, Hricak H, Panebianco V, Witjes JA. Advances in magnetic resonance imaging: how they are changing the management of prostate cancer. Eur Urol 2011;59:962-77.

29. Mazaheri Y, Shukla-Dave A, Goldman DA, Moskowitz CS, Takeda T, Reuter VE, Akin O, Hricak H. Characterization of prostate cancer with MR spectroscopic imaging and diffusion-weighted imaging at 3 Tesla. Magn Reson Imaging 2019;55:93-102.

30. Leapman MS, Wang ZJ, Behr SC, Kurhanewicz J, Zagoria RJ, Carroll PR, Westphalen AC. Impact of the integration of proton magnetic resonance imaging spectroscopy to PI-RADS 2 for prediction of high grade and high stage prostate cancer. Radiol Bras 2017;50:299-307.

31. Gibbs P, Tozer DJ, Liney GP, Turnbull LW. Comparison of quantitative T2 mapping and diffusion-weighted imaging in the normal and pathologic prostate. Magn Reson Med 2001;46:1054-8.

32. Barentsz JO, Richenberg J, Clements R, Choyke P, Verma S, Villeirs G, Rouviere O, Logager V, Fütterer JJ. European Society of Urogenital Radiology. ESUR prostate MR guidelines 2012. Eur Radiol 2012;22:746-57.

33. Weinreb JC, Barentsz JO, Choyke PL, Cornud F, Haider MA, Macura KJ, Margolis D, Schnall MD, Shtern F, Tempany CM, Thoeny HC, Verma S. PI-RADS Prostate
Imaging - Reporting and Data System: 2015, Version 2. Eur Urol 2016;69:16-40.

34. Zakian KL, Sircar K, Hricak H, Chen HN, Shukla-Dave A, Eberhardt S, Muruganandham M, Ebora L, Kattan MW, Reuter VE, Scardinoa PT, Koutcher JA. Correlation of proton MR spectroscopic imaging with gleason score based on step-section pathologic analysis after radical prostatectomy. Radiology 2005;234:804-14.

35. Heuck A, Scheidler J, Sommer B, Graser A, MüllerLisse UG, Massmann J. MR imaging of prostate cancer. Radiologe 2003;43:464-73.

36. Yu KK, Scheidler J, Hricak H, Vignero DB, Zaloudek CJ, Males RG, Nelson SJ, Caroll PR, Kurhanewicz J. Prostate cancer: prediction of extracapsular extension with endorectal MR imaging and three-dimensional proton MR spectroscopic imaging. Radiology 1999;213:481-8.

37. Thörmer G, Otto J, Horn LC, Garnov N, Do M, Franz T, Stolzenburg JU, Moche M, Kahn T, Busse H. Noninvasive estimation of prostate cancer aggressiveness using diffusion-weighted MRI and 3D proton MR spectroscopy at 3.0 T. Acta Radiol 2015;56:121-8.

38. Polanec SH, Pinker-Domenig, K, Brader P, Georg D, Shariat S, Spick C, Susani M, Helbich TH, Baltzer PA. Multiparametric MRI of the prostate at $3 \mathrm{~T}$ : Limited value of 3D (1)H-MR spectroscopy as a fourth parameter. World J Urol 2016;34:649-56.

39. Zhang J, Xiu J, Dong Y, Wang M, Han X, Qin Y, Huang Z, Cai S, Yuan X, Liu Q. Magnetic resonance imaging-directed biopsy improves the prediction of prostate cancer aggressiveness compared with a 12-core transrectal ultrasound-guided prostate biopsy. Mol Med Rep 2014;9:1989-97.

40. Nagarajan R, Margolis D, Raman S, Sheng K, King C, Reiter R, Thomas MA. Correlation of Gleason scores with diffusion-weighted imaging findings of prostate cancer. Adv Urol 2012;2012:374805.

41. Costa DN, Pedrosa I, Roehrborn C, Rofsky NM. Multiparametric magnetic resonance imaging of the prostate: technical aspects and role in clinical management. Top Magn Reson Imaging 2014;23:243-57.

42. Giskeødegård GF, Bertilsson H, Selnæs KM, Wright AJ, Bathen TF, Viset T, Halgunset J, Angelsen A, Gribbestad IS, Tessem MB. Spermine and citrate as metabolic biomarkers for assessing prostate cancer aggressiveness. PloS One 2013;8:e62375.

43. Thomsen FB, Brasso K, Klotz LH, Røder MA, Berg $\mathrm{KD}$, Iversen P. Active surveillance for clinically localized prostate cancer--a systematic review. J Surg Oncol 
2014;109:830-5.

44. Donadon M, Lopci E, Galvanin J, Giudici S, Del Fabbro D, Lanza E, Pedicini V, Chiti A, Torzilli G. Prognostic value of metabolic imaging data of $11 \mathrm{C}$-choline PET/CT in patients undergoing hepatectomy for hepatocellular carcinoma. Cancers (Basel) 2021;13:472.

45. Awwad HM, Geisel J, Obeid R. The role of choline in prostate cancer. Clin Biochem 2012;45:1548-53.

46. Puech P, Villers A, Ouzzane A, Lemaitre L. Prostate cancer: Diagnosis, parametric imaging and standardized report. Diagn Interv Imaging 2014;95:743-52.

47. Lagemaat MW, Zechmann CM, Fütterer JJ, Weiland E, Lu J, Villeirs GM, Holshouser BA, van Hecke P, Lemort M, Schlemmer HP, Barentsz JO, Roell SO, Heerschap A, Scheenen TWJ. Reproducibility of 3D 1H MR spectroscopic imaging of the prostate at 1.5T. J Magn Reson Imaging 2012;35:166-73.

48. Balique J, Cuilleron M, Veyret C. MR spectroscopy of the prostate with external surface coils: clinical feasibility. J Radiol 2010;91:207-12.

49. Bellomo G, Marcocci F, Bianchini D, Mezzenga E, D'Errico V, Menghi E, Zannoli R, Sarnelli A. MR spectroscopy in prostate cancer: New algorithms to optimize metabolite quantification. PloS One 2016;11:e0165730.

50. Starobinets O, Simko JP, Kuchinsky K, Kornak J, Carroll PR, Greene KL, Kurhanewicz J, Noworolski SM.

Cite this article as: Deal $\mathrm{M}$, Bardet F, Walker PM, de la Vega MF, Cochet A, Cormier L, Bentellis I, Loffroy R. Three-dimensional nuclear magnetic resonance spectroscopy: a complementary tool to multiparametric magnetic resonance imaging in the identification of aggressive prostate cancer at 3.0T. Quant Imaging Med Surg 2021;11(8):3749-3766. doi: 10.21037/qims-21-331
Characterization and stratification of prostate lesions based on comprehensive multiparametric MRI using detailed whole-mount histopathology as a reference standard. NMR Biomed 2017. doi: 10.1002/nbm.3796.

51. Steinseifer IK, van Asten JJA, Weiland E, Scheenen TWJ, Maas MC, Heerschap A. Improved volume selective (1) H MR spectroscopic imaging of the prostate with gradient offset independent adiabaticity pulses at 3 tesla. Magn Reson Med 2015;74:915-24.

52. Tayari N, Steinseifer IK, Selnæs KM, Bathen TF, Maas MC, Heerschap A. High-quality 3-dimensional $1 \mathrm{H}$ magnetic resonance spectroscopic imaging of the prostate without endorectal receive coil using a semi-LASER sequence. Invest Radiol 2017;52:640-6.

53. Smith CP, Harmon SA, Barrett T, Bittencourt LK, Law YM, Shebel H, An JY, Czarniecki M, Mehralivand S, Coskun M, Wood BJ, Pinto PA, Shih JH, Choyke PL, Turkbbey B. Intra- and interreader reproducibility of PIRADSv2: A multireader study. J Magn Reson Imaging 2019;49:1694-703.

54. Vandergrift LA, Decelle EA, Kurth J, Wu S, Fuss TL, DeFeo EM, Halpern EF, Taupitz M, McDougal WS, Olumi AF, Wu CL, Cheng LL. Metabolomic prediction of human prostate cancer aggressiveness: magnetic resonance spectroscopy of histologically benign tissue. Sci Rep 2018;8:4997. 